\title{
Review
}

\section{Development of social systems neuroscience using macaques}

\author{
By Masaki IsODA, ${ }^{* 1, * 2, \dagger}$ Atsushi NORITAKE*1,*2 and Taihei NinOMIYA*1,*2 \\ (Communicated by Nobutaka HirokawA, M.J.A.)
}

\begin{abstract}
This paper reviews the literature on social neuroscience studies using macaques in the hope of encouraging as many researchers as possible to participate in this field of research and thereby accelerate the system-level understanding of social cognition and behavior. We describe how different parts of the primate brain are engaged in different aspects of social information processing, with particular emphasis on the use of experimental paradigms involving more than one monkey in laboratory settings. The description begins with how individual neurons are used for evaluating socially relevant information, such as the identity, face, and focus of attention of others in various social contexts. A description of the neural bases of social reward processing and social action monitoring follows. Finally, we provide several perspectives on novel experimental strategies to help clarify the nature of interacting brains under more socially and ecologically plausible conditions.
\end{abstract}

Keywords: social cognition, social behavior, electrophysiology, monkeys, brain

\section{Introduction}

Humans are social in nature. This aspect of human nature has likely contributed to their success as a species in the animal kingdom. ${ }^{1), 2)}$ It can be reasoned that human brain functions are best understood under social conditions. Indeed, increasing attention is being paid to understanding the neural basis of social cognition and behavior, giving birth to the field of social neuroscience. Owing to the refinement of noninvasive neuroimaging techniques, such as functional magnetic resonance imaging (fMRI), neuroscientists are now capable of identifying brain structures and circuits that underlie social cognitive processing in physiology and disease. ${ }^{3)-8)}$ This advancement has made social neuroscience as truly an exciting field as basic and clinical sciences.

*1 Division of Behavioral Development, Department of System Neuroscience, National Institute for Physiological Sciences, National Institutes of Natural Sciences, Okazaki, Japan.

$* 2$ Department of Physiological Sciences, School of Life Science, The Graduate University for Advanced Studies (SOKENDAI), Hayama, Japan.

Correspondence should be addressed: M. Isoda, Division of Behavioral Development, Department of System Neuroscience, National Institute for Physiological Sciences, National Institutes of Natural Sciences, 38 Myodaiji, Okazaki, Aichi 444-8585, Japan (e-mail: isodam@nips.ac.jp).
To further advance social neuroscience research, studies on human subjects are surely indispensable, because they can most directly tell us about our social mind. However, research using other animal species is also of importance. Social neuroscience now encompasses a wide range of methodologies and species, each of which has unique advantages ${ }^{8)}$ and complements the others. For example, insects are ideal for studying specific group behaviors and their genetic bases. ${ }^{9)}$ Rodents offer great opportunities for utilizing and advancing optogenetic technologies, ${ }^{10)}$ thereby demonstrating a cause-and-effect relationship between neural activity and social behavior. Nonhuman primates serve as a more ecologically valid model, owing to their social behaviors and environments being most similar to humans. ${ }^{11)}$ Importantly, humans and macaques share striking resemblances between their brain structures and neural circuits dedicated to social functioning. ${ }^{12), 13)}$ Neuroimaging studies have shown that individuals living in larger social groups - both humans and macaques - have larger gray matter volumes in the amygdala, superior temporal sulcus (STS), and the dorsal and anterior portions of the prefrontal cortex. ${ }^{14)}$-17) These brain regions may be closely linked to social cognitive skills common to several primate species. ${ }^{12)}$ A reasonable next step is the investigation of cellular mechanisms underlying social cognition and behavior. 
Characterizing the functional properties of individual neurons while macaque monkeys perform well-designed social tasks in the laboratory has become technically feasible. As will be outlined later, macaques spontaneously gather social information, such as others' sex, facial expression, and gaze direction. They monitor the actions that are chosen by others and the consequences of these actions. They learn a great deal by observing others. They control their behavior in accordance with current social contexts, such as hierarchical relationships. The refinement of social task paradigms, together with established neural recording at fine spatiotemporal resolutions, has now made it possible to investigate the cellular bases of social brain functions using macaques as a valid model system of human social cognition. The purpose of this review is to provide an overview of rapid developments in social systems neuroscience research using macaques and to discuss several important issues to advance this field of research in more fruitful ways.

In the following sections, we will summarize the neural coding of important aspects related to social cognition - that is, the coding of information value, others' face and gaze, social states, rewards, and actions under social conditions. These topics will be addressed one by one, some of which being presented with a more in-depth description of behavioral tasks before introducing experimental findings: specifically, a pay-per-view task for studying social information valuation, a reward-allocation task for studying social reward processing, and a role-reversal choice task for studying social action processing. The designs of these tasks are unique and have had a notable impact on the development of social experimental paradigms using macaques.

\section{Valuation of social information}

Macaques need to collect socially relevant signals about the outer world and put appropriate value on them to guide adaptive social behavior. For example, macaques have a strict hierarchical organization within each herd; judging a hierarchical relationship between oneself and others is crucial for avoiding unnecessary fights. The selection of appropriate mating partners increases individual fitness. To investigate macaques' preferences for social signals, an experimental paradigm, called the pay-per-view task, was devised. ${ }^{18)}$

In this paradigm, male macaques performed a choice task pitting fluid rewards against brief presentations of visual information. In each trial, a monkey was asked to shift their gaze to one of two simultaneously presented targets. Orienting to target 1 yielded only a juice reward and orienting to target 2 yielded the same or different amount of reward and the appearance of an image consisting of the faces of high-status macaques, the faces of lowstatus macaques, the perinea of female macaques, or a gray rectangle. The investigators then measured the amount of juice sacrificed or gained when a subject was equally likely to choose targets 1 or 2 . Of note, male macaques sacrificed rewards to view female perinea and the faces of high-status monkeys but required reward overpayment to view the faces of low-status monkeys. This finding indicated that macaques spontaneously discriminated between, and put different values on, social signals based on visual information.

Several studies suggested that the valuation of social signals is implemented in several cortical areas. Experimental lesions made in the gyral division of the anterior cingulate cortex (ACCg) affect normal patterns of social interest in other male or female macaques. ${ }^{19)}$ Neurons in the orbitofrontal cortex (OFC) signal the value of social information; in the OFC, neurons conveying social information were more prevalent than neurons conveying information regarding fluid rewards. ${ }^{20)}$ These social-value-coding neurons are located in both the medial and lateral OFC $;^{20)}$ however, lesions made in the medial OFC did not impair social valuation at the behavioral level. ${ }^{19), 21)}$ Finally, neurons in the lateral intraparietal (LIP) area encoded the value of social information when this value signal was used to guide a decision about where to look. ${ }^{22)}$ These findings suggested that neurons in the ACCg and OFC assess the value of information about conspecifics, and LIP neurons use value signals to guide subsequent visual exploration behavior.

During the pay-per-view task, looking at female hindquarters was considered rewarding, because male monkeys looked at them for longer than any other stimulus. ${ }^{18), 22)}$ Conversely, looking at the highranking males was considered threatening, because monkeys looked away from them more quickly. ${ }^{18)-22)}$ Thus, the activity of LIP neurons does not seem to reflect a hedonic valence of social stimuli, but rather signals the behavioral salience or significance of social stimuli for the observer. Where in the brain such a salience signal is computed is an important question for future work. A candidate for the source of such a salience signaling is dopaminergic neurons in the midbrain; these neurons especially in the 
dorsolateral portion of the substantia nigra pars compacta encode motivational salience rather than motivational value. ${ }^{23)}$

\section{Processing of another's facial region}

Faces are inherent social stimuli. Face perception can facilitate interpersonal communication at two levels. The perception of invariant face properties facilitates recognition of individual identity (who someone is), and the perception of changeable aspects of the face, such as expression, head orientation, and eye gaze, facilitates the inference of the mental states of the observed individual (what someone feels and intends). Attention to and perception of the face are skills critical for daily social functioning and communication.

2.1. Face processing. Macaques have a set of face-selective regions in the temporal cortex that can be identified by $\mathrm{fMRI}^{24)-26)}$ or single-neuron recording. ${ }^{27)-30)}$ These 'face patch' regions are located mostly within or close to the STS. ${ }^{29), 31)}$ Neurons within face patches respond to both static faces and faces in motion, with the responses being larger to the latter stimuli. ${ }^{32}$ Face patches form strong, specific connections to one another, indicating that functional specialization in the inferior temporal lobe exists not only at the level of isolated neuronal columns $^{33), 34)}$ or patches, ${ }^{25), 35)}$ but also extends to the level of distributed networks. Neurons in the face patches responding to the face are called 'face neurons', and their response properties vary depending on the anatomical locations of the patches. For example, face neurons in the middle patches are view-specific (e.g., differential responses to rightside and left-side profiles of the same individual); face neurons in the anterior patch are tuned to identity, mirror-symmetrically, across views; and face neurons in the most anterior patches achieve almost full view invariance. ${ }^{36)}$ Notably, in the middle face patch (located $\sim 6 \mathrm{~mm}$ anterior to the interaural line), almost all visually responsive neurons are face selective. ${ }^{30}$ ) This face patch is thought to be homologous to the fusiform face area in humans. ${ }^{37}$ )

Electrical stimulation of the face patches can activate the amygdala, claustrum, and pulvinar, ${ }^{31)}$ suggesting that these subcortical structures may also play a role in face processing. In support of this view, neurons in the amygdala prominently respond to faces. Notably, this response is observed only when monkeys fixate the face, and response latencies are shortest when fixating on the face of the subject's own species. ${ }^{38)}$ This finding was similar to the response properties of 'eye cells' found in the monkey amygdala, which selectively responded to fixations on the eyes of another monkey. ${ }^{39)}$ Clusters of faceselective neurons can also be identified within subregions of the prefrontal cortex that receive temporal lobe afferents - the orbitofrontal cortex (within or nearby the lateral orbital sulcus), the inferior convexity below the principal sulcus, and the anterior bank of the lower arcuate sulcus. ${ }^{40)-42)}$ Neurons in the lateral orbital face patch responded more strongly to expressive faces than to neutral ones. ${ }^{42)}$ Other prefrontal and temporal lobe face patches were only weakly modulated by facial expression. ${ }^{42)}$ The lateral orbital face patch may, therefore, have a unique role in processing the emotional content of the face.

Several studies have consistently demonstrated right hemisphere superiority in monkeys for processing facial information, ${ }^{43)-45)}$ similar to humans. ${ }^{37), 46), 47)}$ Consistent with these reports, the posterior face area shows a more extensive fMRI activation in the right hemisphere than in the left hemisphere in macaques. ${ }^{26)}$ These findings suggested a hemispheric asymmetry in the processing of face information in both macaques and humans. Damage to the posterior right hemisphere in humans can produce prosopagnosia. ${ }^{48)}$ The right-dominant organization might be associated with the 'left field advantage' for face recognition; human subjects process face information faster when presented to the left hemifield than to the right hemifield. ${ }^{49)}$

An obvious question for future work is how the brain regions discussed above interact during processing facial information. While simultaneous singleunit recording from multiple regions is one way to assess inter-areal interactions, whole brain imaging, whether it is functional or anatomical, would help to evaluate the neural networks underlying facial information processing including the hemispheric asymmetry.

2.2. Gaze processing. The gaze direction of others provides useful information about their focus of attention and hidden intention. ${ }^{50), 51)}$ Macaque monkeys demonstrate a preference to view the eye region in the others' face similar to humans, and are sensitive to the direction of others' gaze directions. ${ }^{52)}$ The temporal cortex, especially the anterior superior temporal sulcus (STSa), plays a central role in processing the direction of others' eye gaze. Many neurons in the STSa are selective for, or influenced by, the direction of others' gaze, ${ }^{53), 54)}$ and bilateral removal of the banks and floor of the STS reduces the accuracy of eye gaze perception. ${ }^{55)}$ STSa neurons also 
exhibit differential activity depending on the view of the face ${ }^{53), 56), 57)}$ and body. ${ }^{57)}$ In particular, neurons in the more anterior part respond optimally to a single oblique view; conversely, facial views that elicit optimal responses are distributed among all views in the more posterior part. ${ }^{57)}$ These findings suggested that the STSa has a critical role in assessing the focus of attention of others. Neurons exhibiting similar response properties were also identified in the amygdala (especially the lateral part), ${ }^{58)}$ which has reciprocal connections with the STS. ${ }^{59)}$

Gaze behavior is not just a movement of a body part, but provides a window into the social mind. Gaze behavior in social contexts, such as gazefollowing and joint attention, is considered a foundation for more sophisticated social skills, such as having a theory of mind. ${ }^{50), 51), 60)}$ Despite some intensive debate, ${ }^{61)}$ it now seems likely that these social gaze behaviors can also be observed in macaques. ${ }^{62)-67)}$ Low-status male macaques reflexively followed the gaze of all familiar conspecifics, but high-status macaques did so only selectively for the gaze of other high-status monkeys. ${ }^{63)}$ This finding led to the hypothesis that gaze-following behavior involves reflexive and voluntary components and that the strength of these mechanisms varies according to social status. ${ }^{63)}$ Notably, intranasal administration of oxytocin to monkeys increased the frequency of gaze following responses while viewing videos of conspecifics displaying natural behaviors. ${ }^{67)}$

Several lines of evidence suggest that the STS is involved at least in gaze following. An fMRI study found that active gaze-following toward an object in space activated the fundus and lower bank of the middle STS bilaterally (STSm; 0.8-6.4 mm anterior to the interaural line). ${ }^{68)}$ This 'gaze-following patch' is close to but located outside the face patches. Muscimol-induced reversible inactivation of the fundus and dorsal bank of the posterior STS (STSp; between $2.0 \mathrm{~mm}$ anterior to and $2.0 \mathrm{~mm}$ posterior to the interaural line) suppressed gaze following. ${ }^{69)}$ Neurons in the STSm and STSp seem to project to the LIP, ${ }^{70)}$ a cortical area associated with attention and eye movement. ${ }^{71)}$ Notably, a subset of neurons in the macaque LIP fired both when animals looked in the preferred direction of the neuron and when the observed animals looked in the preferred direction of the neuron. ${ }^{72)}$ Together, the STS-LIP network may underlie the sharing of attention between self and others. The STS-LIP network is connected with extrastriate visual cortices, ${ }^{73)-75)}$ activity of which is known to be modulated by attention. ${ }^{76), 77)}$ Thus, it is of interest to examine whether extrastriate cortical activity is influenced by others' gaze information. It can be argued that the assignment of mental states to biological beings, but typically not to man-made objects, is a unique aspect of social cognition. We speculate that at least a subset of neurons in extrastriate visual cortices may exhibit enhanced responses to biological stimuli, such as the eye, mouth, or faces, thereby contributing to reflexive orienting to social cues.

\section{Information about social states}

Social behaviors are governed by hierarchical relationships with other conspecifics. Subordinate animals show submissive behaviors, such as refraining from acting to compete against dominant monkeys, for example, for food. However, subordinate animals do not always display this behavioral pattern; when dominant monkeys are not present nearby, or when dominant monkeys are present but show no sign of their dominance, subordinate monkeys do acquire food items. ${ }^{78)}$ Macaque behavior can be shaped by both a stable social hierarchy and a momentary social context, or 'social state'. ${ }^{79)}$

Neurons in several brain regions show social state-dependent activity while performing a foodgrab task. Here, two monkeys shared a common space and reached for the same food item. ${ }^{80)}$ In the caudate nucleus of the basal ganglia, a group of neurons decreased their 'task-related' activity during a submissive state in which active food taking was suppressed by the presence of a dominant monkey. ${ }^{81)}$ This activity change could not be explained by a reward or motor factor. In the dorsolateral prefrontal cortex, a social state-dependent modulation was observed in the 'baseline' activity; sustained activity increased during a dominant state and decreased during a submissive state. Electrocorticographic recordings from a wide range of cortical areas showed that neural coding of the social state develops as the conflict between two monkeys increases during the food-grab task. ${ }^{82)}$ Before a food item is presented, the parietal and sensorimotor cortices show sustained activity reflective of the social state; after the presentation, the prefrontal and visual cortices start to exhibit social state-dependent activity.

MRI studies demonstrated that social status is associated with structure and function in several brain regions ${ }^{14), 83)}$ (Fig. 1). Specifically, higher social rank is associated with larger gray matter volume in the rostral prefrontal cortex, mid-STS extending into the inferior temporal gyrus, amygdala, postero- 

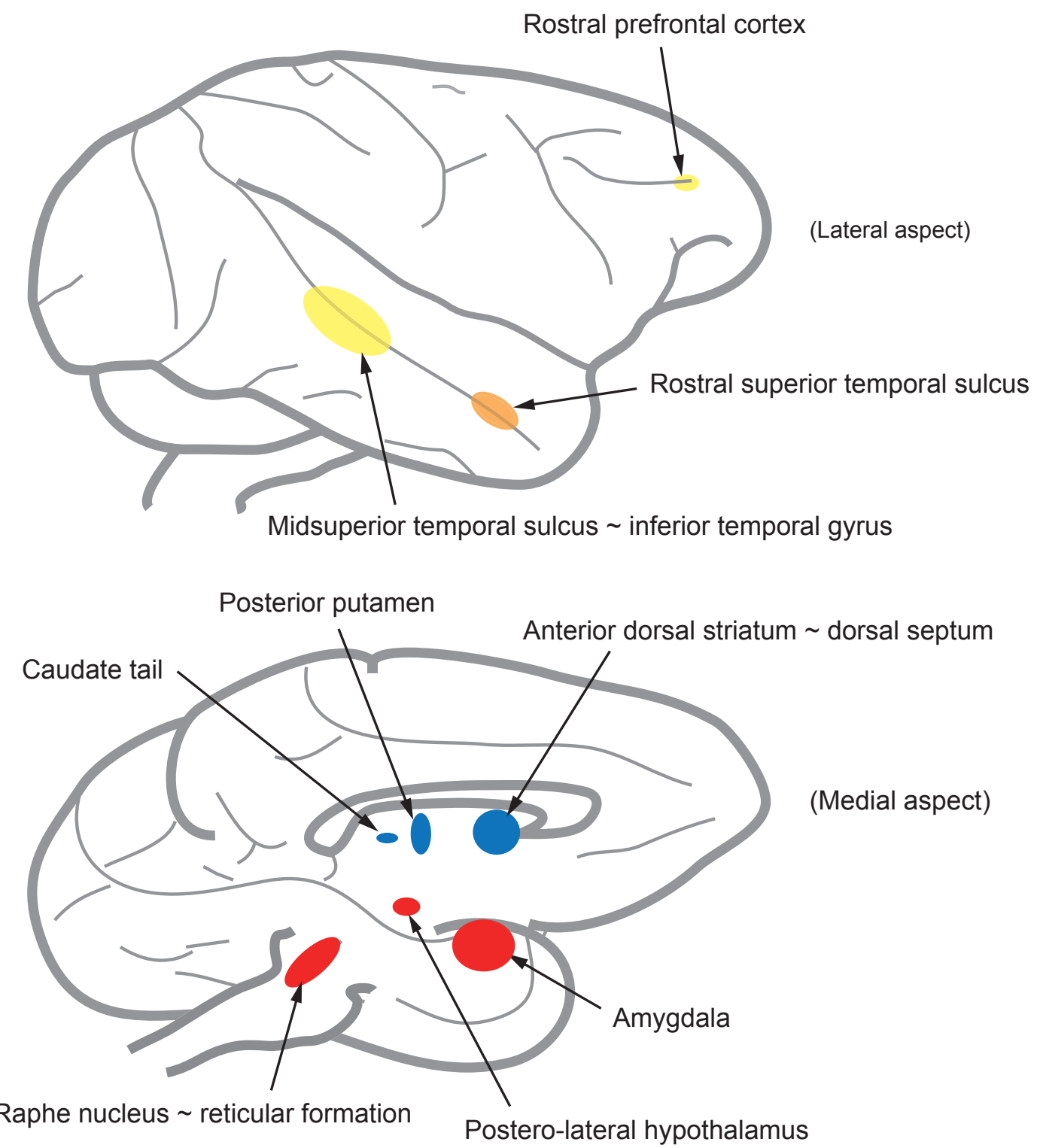

Raphe nucleus $\sim$ reticular formation

Postero-lateral hypothalamus

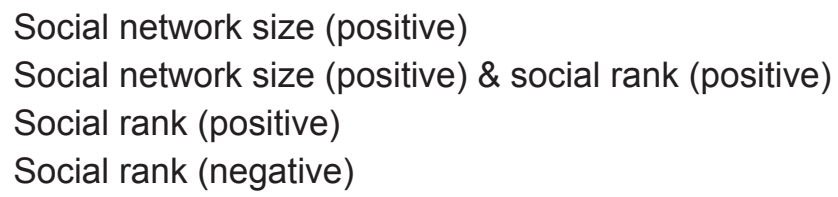

Social network size (positive)

Social network size (positive) \& social rank (positive)

Social rank (positive)

Social rank (negative)

Fig. 1. Brain regions showing increasing (positive) or decreasing (negative) gray matter volume associated with increasing social network size and/or social rank. Social network size refers to the number of housemates of each monkey. See the inset for social factors correlated with each region's volume (social network size or social rank) and signs of correlation (positive or negative).

lateral hypothalamus, raphe nucleus, and reticular formation. Conversely, lower social rank is associated with larger gray matter volumes in the dorsal septum, anterior dorsal striatum, and caudate tail.
Among these regions, the volume of the rostral prefrontal cortex and mid-STS/inferior temporal gyrus is also associated with the size of the social network size (the number of housemates of each 
monkey). Of note, cortical areas in the mirror system, an important component of social brain networks (see Section 5.1) did not show a volume change associated with social rank or social network size. An important issue for future work is to determine whether the social state signals in cortico-subcortical regions reflect internal states, such as emotional responses, or are the control signal regulating adaptive social behavior.

\section{Reward encoding in social contexts}

What happens to others shapes the behaviors of the observer and promotes observational learning in humans. ${ }^{84), 85)}$ In macaques, too, the occurrence of pleasant or unpleasant outcomes for others affects social decisions of the observer, ${ }^{86}$ and learning to perform a certain task can be facilitated by observing others' experiences of performing the same task. ${ }^{87)-90)}$ A study using a reward-allocation task examined how outcomes for others affected observers' decisionmaking. ${ }^{91)}$ Here, two monkeys sitting close to each other were conditioned with different visual cues, each of which was uniquely associated with a reward to only self (M1), only another monkey (M2), both M1 and M2, or no one. Once the conditioning was established, the monkeys were asked to freely choose one of the cues by shifting their gaze. The authors found a choice bias in which M1 preferred cues paired with rewards to M2 over cues paired with reward to no one. By contrast, M1 preferred cues paired with rewards to itself over cues paired with rewards to both M1 and M2. Of note, the exogenous administration of oxytocin increased the frequency of M1's prosocial choices associated with rewards to M2 when the alternative was to reward no one, but promoted selfish choices when the alternative was to reward itself. ${ }^{92)}$ These findings suggested that other-regarding preferences are context-dependent and in some way under the control of oxytocin.

A subsequent recording experiment showed area-selective reward processing in the primate brain. Neurons in the OFC preferentially processed rewards to oneself, neurons in the sulcus division of the ACC (ACCs) preferentially processed rewards to non-self (other or no one), while those in the ACCg processed self-rewards, other's rewards, or both-rewards. ${ }^{93)}$ These findings are consistent, in part, with the finding that lesions in the ACCg impair the valuation of social information. ${ }^{19)}$ A follow-up study using the reward-allocation task demonstrated that neuronal activity in the basolateral amygdala (BLA) reflected the value of other's rewards in the same way it reflected the value of one's own rewards when animals guided a decision of whom to reward. ${ }^{94}$ Notably, injection of oxytocin in the unilateral BLA increased the frequency of prosocial decisions. ${ }^{94)}$ The amygdala has been implicated in social cognition, as discussed earlier, such as processing observed facial expressions and gaze, in both humans and nonhuman primates. ${ }^{39), 58), 95)-97)}$ Similar to OFC neurons, striatal neurons primarily encode rewards for oneself. Notably, the self-reward-related activity in the striatum differs depending on whether the self-reward is produced by one's own action or by the other's action. ${ }^{98)}$

The neural signature representing one's own rewards may differ depending on whether they are acquired through competition. Neuronal activity in the dorsolateral prefrontal cortex (dlPFC) substantiates this. A study using a video shooting game with another conspecific found that reward-related responses of dlPFC neurons were significantly greater in competitive conditions than in the noncompetitive condition. ${ }^{99)}$ Of note, the great majority of these reward-related responses were significantly larger in competition against another monkey than against a computer. ${ }^{99)}$ There are also other subsets of dlPFC neurons that seem to encode reward contexts in the game, reflecting either an egalitarian competitive context in which both the winner and loser, or neither of them, will be rewarded, or a typical competitive condition in which only the winner will be rewarded. ${ }^{100)}$

Egalitarian competitive contingency also profoundly affects monkeys' motivation. In the above study using the video shooting game, behavioral performance - both the success rate for and the latency of the first shot - significantly deteriorated in the egalitarian competitive contexts compared with the typical competitive context. ${ }^{100)}$ Another study showed, however, that such 'egalitarian effects' on behavior and neuronal activity are not confined to a competitive context. ${ }^{101)}$ Here, the actor monkey, sitting in front of the observer, was asked to release a lever within a short period of time when a GO signal was given. The actor performed this motor task in two conditions. In one, the correct response resulted in a reward only to itself (individual reward); in the other, the correct response resulted in a reward to both itself and another (joint reward). Note that the task situation was not competitive, and the workload was the same for the actor in the two conditions, at least objectively. Notably, the actor was less willing to work when the joint reward was expected. 


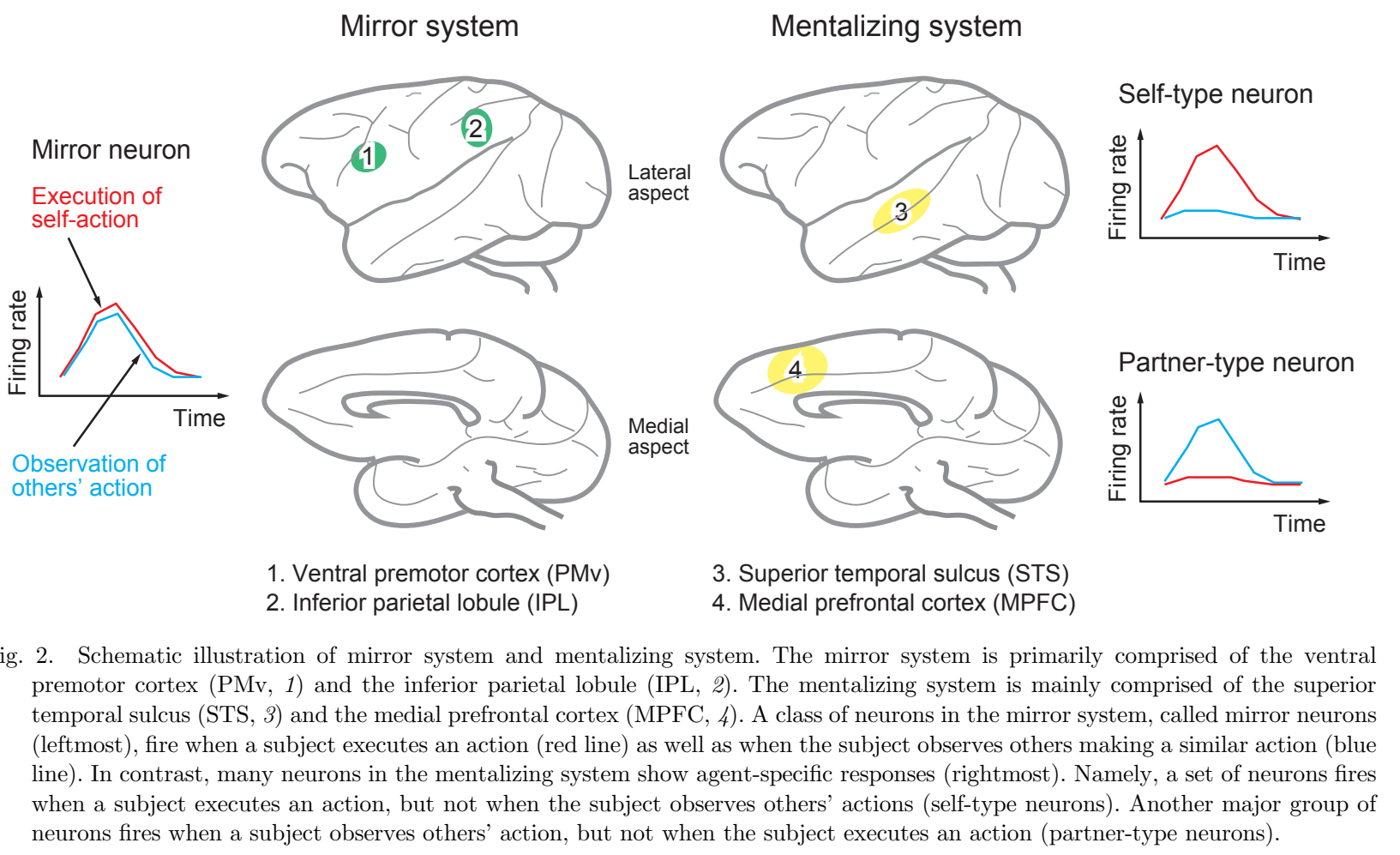

Furthermore, neurons in the OFC (area 13) signaled motivational value of expected rewards in such a way that the joint reward was of lower value despite it being the same absolute amount as the individual reward. Together, these findings suggested that the value of one's own reward is strongly affected by social contexts. A notable question is how the processing of one's own rewards, others' rewards, and joint rewards are mediated by cortico-cortical and/or cortico-subcortical networks. Of crucial importance is to determine whether neurons in the dopaminergic midbrain nuclei - key regions in brain reward networks - have a function in such social reward processing and, if so, how dopaminergic neurons interact with neurons in other corticosubcortical areas.

\section{Action encoding in social contexts}

The action of others is a key window into their unobservable states of mind, such as beliefs, desires, and intentions. The actions of others also provide useful information about what action to take or avoid without trial and error. Like humans, macaques are capable of learning through observation and of then guiding their own adaptive actions. ${ }^{87), 90), 102), 103)}$ The primate brain is equipped with two systems that have functions in monitoring and understanding others' actions $^{104)}$ (Fig. 2). One is the mirror system, and primarily consists of the ventral premotor area $(\mathrm{PMv})$ and the inferior parietal lobule. The other is the mentalizing system, and consists mainly of the STS and the medial prefrontal cortex (MPFC).

5.1. Action encoding in the mirror system. The mirror system has been the subject of electrophysiological studies for more than 25 years since the discovery of 'mirror neurons' in the macaque brain. ${ }^{105)}$ The neurons of this class fire not only when a subject performs a certain action, but also when the subject observes another agent performing the same or a similar action ${ }^{106)}$ (Fig. 2, left). This overlapping encoding of self and others' actions suggests that the visual aspects of a given action performed by the actor correspond to the motor aspects of the same action in the observer at the single-neuron level. Some of the mirror-neurons are pyramidal tract neurons and thus can transmit information about observed actions directly to the spinal cord. ${ }^{107)}$ These response properties raise the interesting possibility, albeit still controversial, ${ }^{108)}$ that mirror neurons are involved in a range of social processes, such as monitoring and understanding others' actions via embodied simulation, ${ }^{109)}$ imitation, ${ }^{110), 111)}$ and empathy. ${ }^{111)}$ Conversely, the dysfunction of mirror neurons is hypothesized to underlie the 
development of autism spectrum disorder (ASD) in humans. ${ }^{110), 112), 113)}$

Mirror neurons in the macaque $\mathrm{PMv}$ show intriguing properties. A small proportion of them (17\%) were activated in advance of the beginning of the observed action when it was predictable. ${ }^{114)} \mathrm{A}$ subset of the mirror neurons that were active during the self-action exhibited decreased activity during action observation ('suppression mirror neurons') ${ }^{115}$ ) or increased activity when the observed action was both executed and withheld ('inaction mirror neurons'). ${ }^{114), 116)}$ Responses of the mirror neurons were modulated by the value of objects grasped during the observed action. ${ }^{117)}$ Activity of the mirror neurons were differentially modulated by the location in space (peripersonal vs. extrapersonal space) or the point of view (first-person vs. third-person perspective) of the observed action. ${ }^{118), 119)}$ A group of location-selective mirror neurons encodes spatial information according to a metric representation, whereas another group encodes spatial information in operational terms. In the latter, mirror neurons changed their discharge rate depending on whether or not the monkey could interact with the action target. ${ }^{118)}$ Finally, the mirror neurons also fired during the perception of abstract causality stimuli. ${ }^{120)}$ Together, these findings suggested that mirror neurons can be involved in several aspects of action understanding, including judging the intentionality of the observed action. ${ }^{121)}$

5.2. Action encoding in the mentalizing system. Successful social interaction depends on not only the ability to identify with others, but also the ability to distinguish between aspects of self and others. ${ }^{122)}$ For example, in social life people need to accurately assign a shared outcome to self-actions or others' actions to determine the optimal level of cooperation. As discussed earlier, mirror neurons respond similarly to the actions of self and others; they are in theory not capable of encoding which social agent is acting. The classical mirror-neuron theory has been silent on how the brain distinguishes between self-actions and others' actions.

fMRI studies on human subjects have suggested that aspects of self and others are differentially processed in the MPFC, a key node in the mentalizing system. ${ }^{4)}$ A meta-analysis of fMRI studies showed that judgements about the self are associated with activation in the ventral MPFC and judgements about others are associated with activation in the dorsal MPFC. ${ }^{104)}$ The z-coordinate of activation foci can predict whether individual studies involve selfrelated judgments or others-related judgments. ${ }^{123)}$
These findings led to the interesting hypothesis that MPFC neurons may provide a distinct neural substrate for the self-actions and others' actions.

To address this issue further, Isoda and coworkers devised an experimental, role-reversal choice task for pairs of monkeys ${ }^{124)}$ (Fig. 3). Here, two monkeys sat face-to-face and monitored each other's actions to optimize their own choice behavior. In each trial, one monkey was assigned the role of the actor and the other monkey the role of the observer (Fig. 3A). After the actor pressed a start button for $1-1.5 \mathrm{~s}$, two target buttons were illuminated in green and yellow, the positions of which were randomly determined. The actor was required to choose one of the targets and the observer had to hold its start button throughout the trial. One of the two target colors was associated with a reward in each trial, which remained the same for a block of 5-17 trials (Fig. 3B). The color-reward contingency was then reversed unpredictably; the actor now had to switch to the color that had been associated with no reward in the preceding block. The roles of the actor and the observer alternated every two trials. Both monkeys obtained a liquid reward (a drop of water) when the actor made the correct choice, and neither monkey was rewarded when the actor made the wrong choice. Behavioral analysis indicated that the monkeys actively monitored and utilized their partner's choice information despite not being instructed to do so.

Single-neuron recordings in the MPFCs of these monkeys distinguished three types of action-coding neurons. ${ }^{124)}$ One group of neurons fired during the monkey's own actions, but not during the partner's actions ('self-type neurons') (Fig. 2, right top); another group fired only during the partner's actions ('partner-type neurons') (Fig. 2, right bottom); and a third set of neurons fired during both the self-actions and partner's actions ('mirror-type neurons'). Among these action-coding neurons, the proportion of the self, partner, and mirror type was $36 \%, 48 \%$, and $16 \%$, respectively. Furthermore, the proportion of partner-type neurons was significantly larger in the dorsal division than in the ventral division of the MPFC. By contrast, the proportion of self-type neurons was significantly larger in the ventral division than in the dorsal division. These findings indicated that the neuronal substrate of action encoding is largely agent-selective in the mentalizing system. It has been shown that neuronal activity during action planning, that is, prior to movement initiation, can also be agent-selective in the dorsal ${ }^{125}$ ) and ventral ${ }^{126)}$ divisions. We proposed that in the 


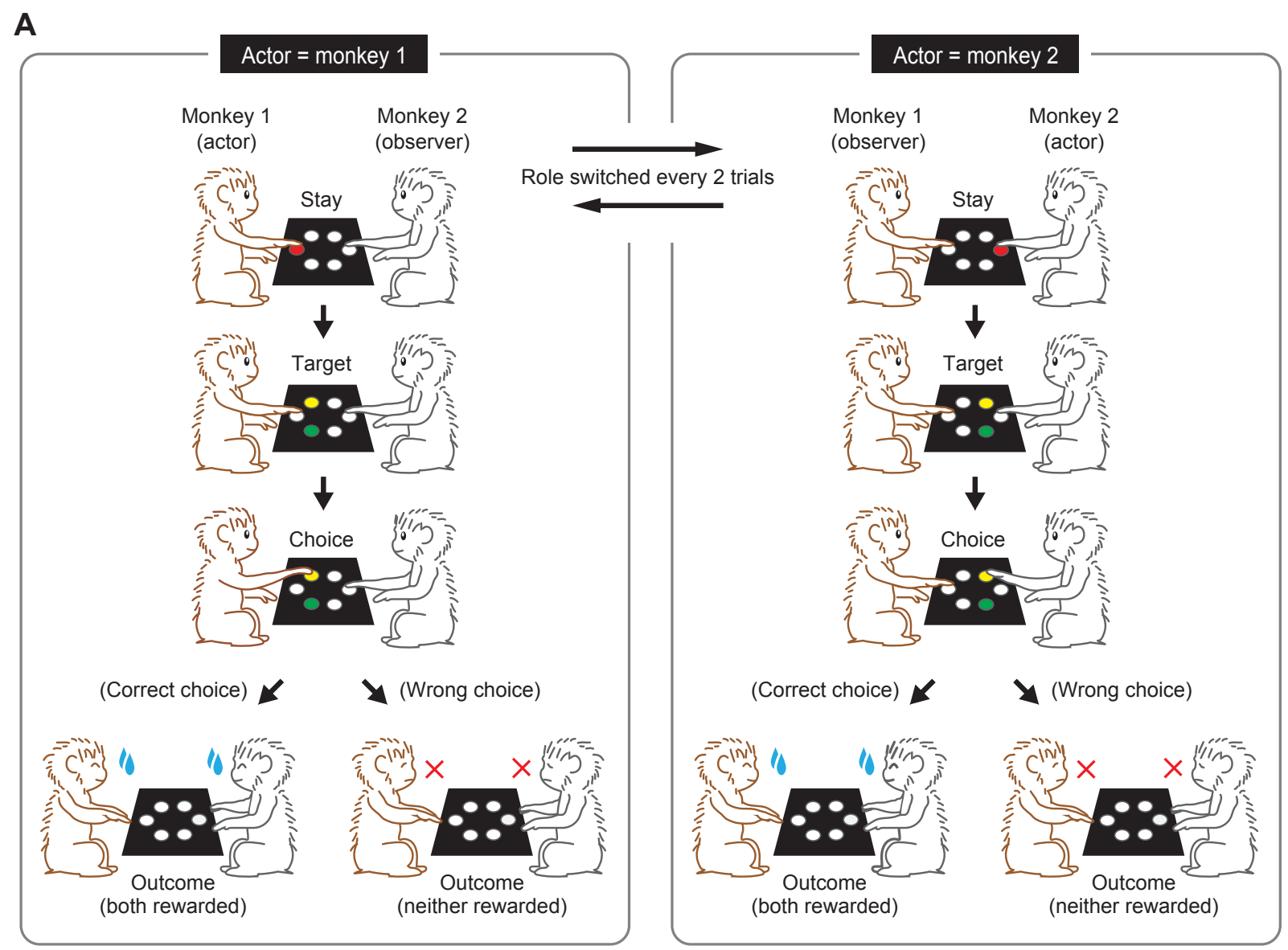

B

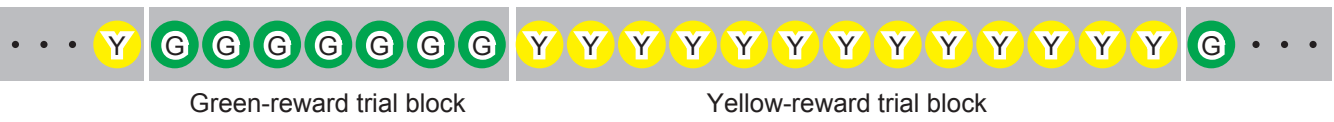

Fig. 3. Temporal sequence of events in a role-reversal choice task. (A) An example of a single trial in which monkey 1 was assigned the role of the actor and monkey 2 the role of the observer (left). The actor role was indicated by illuminating a red start button. After two trials, the roles were switched and monkey 2 was assigned the role of the actor (right). (B) The correct target color (green or yellow) was determined in a block-wise manner. Each colored circle denotes the correct target color in each trial. G, green; Y, yellow. The green and yellow target was associated with a reward in the green-reward and yellow-reward trial block, respectively. The colorreward contingency switched unpredictably every $5-17$ trials.

mentalizing system the MPFC plays an important role in agent-specific performance monitoring in social conditions, be it for overt actions or covert intentions.

Notably, the partner-type neurons and mirrortype neurons were virtually absent in a monkey exhibiting behavioral disorders most similar to ASD in humans, ${ }^{127)}$ suggesting that the dysfunction of others-responsive neurons (partner and mirror types) might underlie the expression of the autistic phenotype. In this autistic monkey, whole-exome sequencing and copy number variation analyses identified rare coding variants in genes (HTR2C and $A B C A 13$ ) linked to human neuropsychiatric and neurodevelopmental disorders. ${ }^{127)}$ The 'broken mirror' hypothesis posits that early developmental failures of mirror neurons may result in the expression of behavioral disorders in ASD. ${ }^{112), 113), 128)}$ Although there is some indirect support for the broken mirror hypothesis in humans, ${ }^{128)-130)}$ direct cellular evidence has not been obtained in either humans or other animals. The monkey with an autistic phenotype provided the first direct evidence for the aberrant population of cortical neurons responding to others' actions in the disorder. 
Phenotype-driven approach

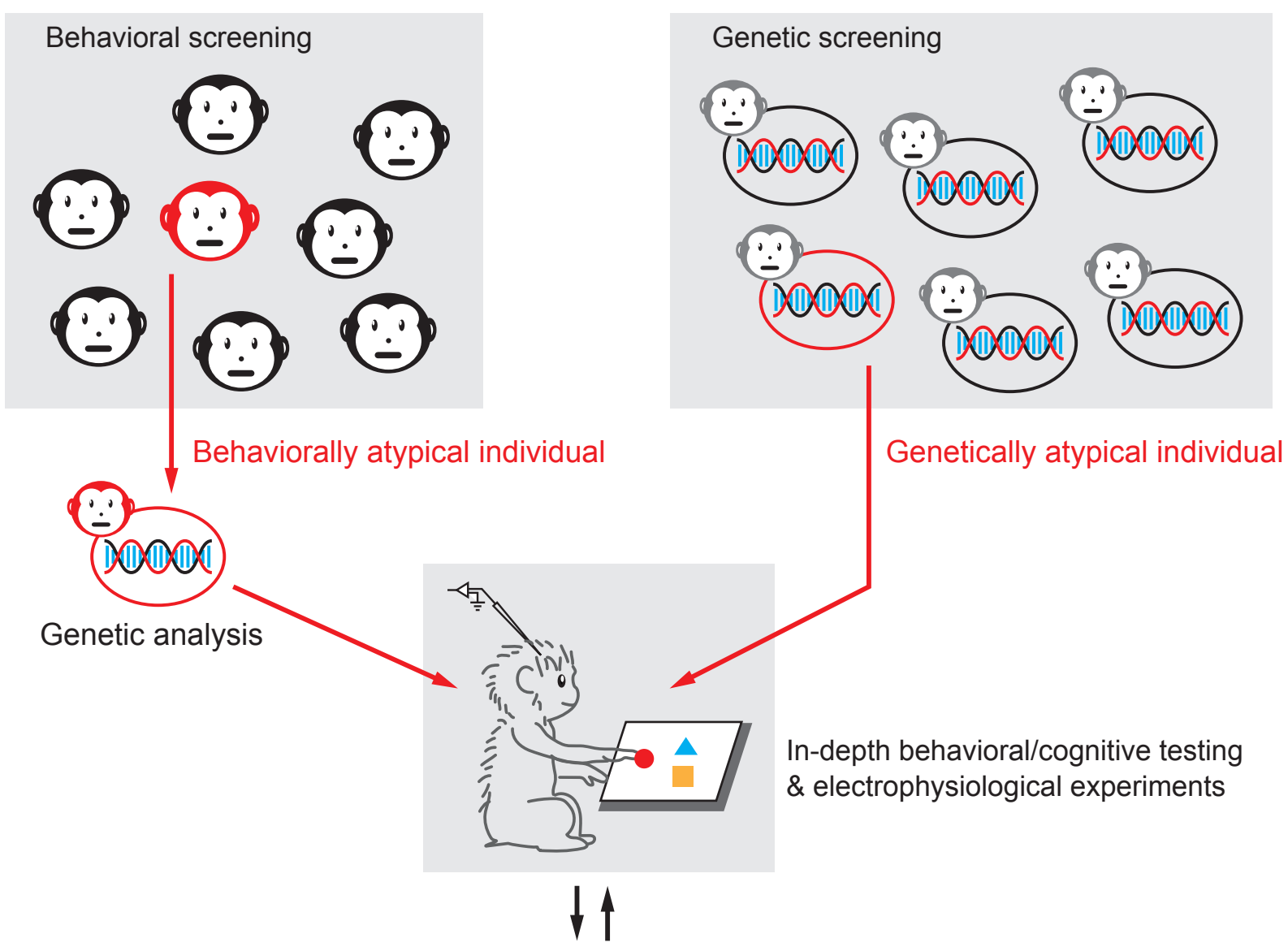

Developing animal models using genetic manipulation
Genotype-driven approach

enetic screening

0000

al

Fig. 4. Two strategies in cognitive genomics research. Up to now, a 'genotype-driven' approach has represented the majority of studies. This approach first involves a genetic screening across a large set of subjects to identify individuals with any polymorphisms of a specific target gene (right). On the other hand, the new 'phenotype-driven' approach begins with behavioral screening to find individuals with atypical, cognitive and/or behavioral traits (left). Genetic analysis is then applied to those individuals to identify possible genetic causes of such atypical behavior. In both approaches, detailed assessment of behavioral and cognitive functions should follow in a laboratory setting, together with electrophysiological experiments to understand the neural basis of any unusual traits. Once a relationship is revealed between particular genotypes and unusual traits, then an animal model expressing such traits can be developed using genetic manipulation, which further allows for neurobiological investigations as a basic research and clinical applications for therapeutic intervention.

The availability of whole-genome sequences at the individual level has created a new discipline called cognitive genomics. ${ }^{131)}$ To date, cognitive genomics research conducted in the macaque has mostly taken a 'genotype-driven' approach (Fig. 4, right), in which genetic screening is performed for a large set of monkeys to identify individuals with particular genetic variants and then their cognitive-emotional traits are evaluated. ${ }^{132)-135)}$ However, there can also be another approach that is 'phenotype-driven' (Fig. 4, left), in which behavioral screening is performed for a large set of monkeys to identify individuals with atypical cognitive-emotional traits, and then genetic analysis is carried out to find possible genetic causes. The cognitive genomics study conducted for the above autistic monkey was the first example of the phenotype-driven approach. Although there is still a large gap between gene, neuron activity, and behavioral phenotype in terms of mechanisms and causality, the refinement and application of cutting-edge technologies for use in macaques will help bridge the gap. For example, 
the creation of an iPS-based model capturing the genetic complexity of a disease condition would promote in vitro studies to clarify neurobiological mechanisms of aberrant neural firing using a diseaserelevant cell type. ${ }^{136), 137)}$ Another possibility includes viral vector mediated gene delivery to the macaque central nervous system to replicate the disease condition in intact animals or to induce a rescue of the disease phenotype. ${ }^{138), 139)}$ Analysis of behavioral changes after circuit-selective interventions will also be of critical importance. ${ }^{140)}$ Monkeys with unusual behavioral traits are generally not considered suitable for use in physiological studies. Future work should now aim to closely examine such monkeys from the behavioral to the neuronal and genetic levels, rather than excluding them as research subjects.

In the role-reversal choice task, a sizable number of MPFC neurons exhibited a phasic increase in activity immediately after the partner had committed a choice error. ${ }^{141)}$ These 'partner-error neurons' were also located in both divisions of the MPFC: the dorsal division, where the partner's error was detected, and the ventral division, where the actor's own correct action after the partner's error was encoded. These findings suggested that the MPFC plays a pivotal role in monitoring the correctness of others' actions for guiding adaptive decisions in social contexts. It has been shown that negative outcomes produced by the actors' choices facilitated the observers' learning. ${ }^{103)}$ The activity of partner-error neurons may, therefore, be critically involved in observational learning. It has also been shown that neurons in the striatum respond to error-related feedback, the magnitude of which differs depending on whether the error is made by oneself or another. ${ }^{142)}$ The striatum receives afferent inputs from the MPFC. ${ }^{143)}$

The information about others' actions represented in the MPFC may arrive there from the STS. A subset of neurons in the STSa selectively responds to others' hand movements but not to one's own hand movements. ${ }^{144)}$ Neurons in the STSa may gather information about others' actions and send it to other brain regions including the MPFC. In support of this hypothesis, the STS directly projects to the MPFC. ${ }^{145)-147)}$ Future work should investigate how the role played by the MPFC and STS in others'-action processing can differ from one another. We hypothesize that neurons in the STS are primarily involved in detecting others' actions and neurons in the MPFC assess the value, appropriateness, and intentionality of others' actions to help guide socially adaptive behavior.

\section{Future perspectives}

As reviewed here, it is now technically feasible to measure and analyze neural activity at the singleneuron and network levels while monkeys perform a variety of social tasks in a laboratory setting. Using such task paradigms, an increasing number of studies have demonstrated how different brain regions participate in different aspects of social cognition and behavior. It is now clear that social brain function is mediated not only by structures originally proposed by the social brain hypothesis, ${ }^{148)}$ such as the amygdala, temporal cortex, and OFC, but also by many other regions including, but not limited to, the MPFC, DLPFC, PMv, and posterior parietal cortex.

There are, however, several, important limitations and unknowns in social neuroscience studies in macaques. First, invasive electrophysiological recordings in macaques have typically been carried out using two or three subjects for each experiment. Although data consistency is confirmed between subjects in most published work, readers need to be aware of limitations derived from a small subject size and carefully interpret the robustness and significance of each study, particularly given individual differences in traits and cognitive abilities. Second, human social behaviors seem to be more diverse and complicated compared with those of the macaque. Human behaviors can be affected by numerous factors or contexts, such as ethics, education, and culture. Therefore, to clarify the neural basis of complex (and higher-order) social behaviors, studies on human subjects are indispensable. In this respect, human and macaque experiments should complement each other to better understand primate social brain functions. Finally, accumulating evidence suggests the existence of functional lateralization of the human brain for mediating social cognition. Specifically, the right hemisphere has an advantage, compared with the left one, in social cognitive processes, such as self-related judgements, detection of social signals, and inference about others' mental states. ${ }^{149), 150)}$ It remains unknown, however, whether such hemispheric lateralization is also present in the macaque brain, simply because of the lack of related studies. Future work should address this fundamental issue to gain insights into possible differences in brain organization between humans and macaques.

We consider it useful to provide several perspectives on novel experimental strategies that could help clarify the nature of interacting brains using macaques. As mentioned above, social cognition and 
behavior are implemented by distributed neural networks; even a single social brain function is implemented by more than one brain region. Most of the published work on macaques have adopted a single-neuron recording technique to examine a single target region, whereas neural recordings and analyses from the network perspective have rarely been done. For example, the mirror and mentalizing systems, both involved in social action processing, have prominent anatomical connections with one another, at least in the macaque brain. ${ }^{147), 151)-153)}$ Therefore, it is natural to assume that interactions should also exist at the functional level between the two systems. There are indeed several neuroimaging studies demonstrating such functional interactions in humans; ${ }^{154-156)}$ however, virtually no studies have addressed this issue in macaques. Simultaneous recording of ensemble neural activities in the mirror and mentalizing systems should help to clarify the nature of their interactions. Network-level analysis of neural activity will also help to clarify how various social signals, such as the face, gaze, reward value, and social states, are integrated in the brain. This issue is fundamental to understanding the organization of social brain networks in both primate species. The integration of others-relevant sensory signals into value information for generating a gaze bias, for example, is hypothesized to be mediated by two distinct but interrelated pathways: a subcortical route mediating crude but fast orienting to animate objects and faces, and a cortical route mediating nuanced and context-dependent social attention. ${ }^{157)}$

Social skills in everyday life are acquired, sophisticated, and implemented through real-time interactions with other individuals. One of the ultimate goals of social neuroscience is to uncover what takes place in dynamically interacting brains of multiple agents. However, the current experimental approach in social neuroscience studies using macaques has been to investigate intra-individual brain dynamics during inter-individual interactions. Here, neural activity is measured from only a single brain at a time, and the focus of analysis is inevitably confined to within-brain mechanisms. Such single brain studies are incapable of discovering as-yetunknown neural processing that might occur during joint task performance, such as between-brain synchrony. A reasonable next step in social systems neuroscience is to understand inter-individual brain dynamics. The 'interactive brain hypothesis' posits that social interaction engages neural processes that either do not occur or are less active during similar solo conditions. ${ }^{158)-160)}$ Indeed, oscillatory coupling of neural signals between two brains has been reported during interactive tasks using fMRI, ${ }^{161), 162)}$ functional near-infrared spectroscopy, ${ }^{163)-167)}$ and electroencephalography ${ }^{168)}$ in humans. Although this technique, called hyperscanning, has not been applied to macaques, simultaneous recording of neural activities in two interacting subjects will provide important insights into the neural underpinnings of synchronous activity with precise spatiotemporal resolution. This new approach will delineate how two brains can work as a single system when two individuals get involved in 'we-mode', an irreducibly collective mode in which interacting persons share their minds. ${ }^{169)}$ In macaques, too, spontaneous synchronization of arm motion $^{170)}$ and eyeblink ${ }^{171)}$ can occur between two subjects during social interactions. Social neuroscientists using macaques should boldly go forward to address this challenging but fascinating issue and establish the field of 'two-brain neuroscience.'

Finally, another novel direction in social neuroscience research using macaques is to assess their behavior and neural activity in more-natural group conditions. Primates, including humans, are highly social creatures, and their perception, cognition, and action are deeply embedded in the social world. It can be conjectured that functions of the primate brain are best understood in social environments, in which multiple agents interact dynamically. With this conjecture in mind, a Japanese team, about 50 years ago, developed an animal model of schizophrenia by chronically injecting methamphetamine into monkeys housed in a big cage, in which 7-9 monkeys were kept together. ${ }^{172)}$ By employing such an experimental design in a natural group context, the investigators observed intriguing social behavioral disorders most similar to human schizophrenia and reported that both acute and chronic symptoms substantially varied according to the social hierarchy of each monkey. More recently, a real-time, multi-camera, 3D tracking system was developed to enable the continuous monitoring of behaviors of socially housed monkeys at a lower hardware cost. ${ }^{173)}$ Using the tracking system, social behavioral changes caused by the introduction of an object (toy) in a group were reported. ${ }^{174)}$ Furthermore, the assessment of social behavioral changes induced by drug injections has also been started under group settings. ${ }^{175)}$ Further refinements of experimental procedures, for both behavioral and neural data collection, are expected with technological advancements. The effective combination of the group-based experimental strategy, 
which is suitable for screening individual social behavioral traits, and the two-monkey laboratory testing strategy, which is suitable for in-depth electrophysiological investigations, will provide a fruitful platform for future social neuroscience research using macaques. This type of research is essential to better understand the mechanisms underlying, and thereby reduce the substantial cost and suffering of, neurodevelopmental as well as psychiatric disorders that are characterized most often by deficits in social communication and interaction.

\section{Acknowledgement}

This work was supported by the Strategic Research Program for Brain Sciences from Japan Agency for Medical Research and Development (JP18dm0107145) to M.I.

\section{References}

1) Dunbar, R.I.M. (2003) The social brain: mind, language, and society in evolutionary perspective. Annu. Rev. Anthropol. 32, 161-181.

2) Herrmann, E., Call, J., Hernandez-Lloreda, M.V., Hare, B. and Tomasello, M. (2007) Humans have evolved specialized skills of social cognition: the cultural intelligence hypothesis. Science $\mathbf{3 1 7}$, 1360-1366.

3) King-Casas, B., Tomlin, D., Anen, C., Camerer, C.F., Quartz, S.R. and Montague, P.R. (2005) Getting to know you: reputation and trust in a two-person economic exchange. Science 308, 7883.

4) Amodio, D.M. and Frith, C.D. (2006) Meeting of minds: the medial frontal cortex and social cognition. Nat. Rev. Neurosci. 7, 268-277.

5) Behrens, T.E., Hunt, L.T., Woolrich, M.W. and Rushworth, M.F. (2008) Associative learning of social value. Nature 456, 245-249.

6) Frith, U. and Frith, C. (2010) The social brain: allowing humans to boldly go where no other species has been. Philos. Trans. R. Soc. Lond., B, Biol. Sci. 365, 165-176.

7) Suzuki, S., Harasawa, N., Ueno, K., Gardner, J.L., Ichinohe, N., Haruno, M. et al. (2012) Learning to simulate others' decisions. Neuron 74, 1125-1137.

8) Stanley, D.A. and Adolphs, R. (2013) Toward a neural basis for social behavior. Neuron 80, 816826.

9) Dobata, S. and Tsuji, K. (2013) Public goods dilemma in asexual ant societies. Proc. Natl. Acad. Sci. U.S.A. 110, 16056-16060.

10) Stamatakis, A.M. and Stuber, G.D. (2012) Activation of lateral habenula inputs to the ventral midbrain promotes behavioral avoidance. Nat. Neurosci. 15, 1105-1107.

11) Tremblay, S., Sharika, K.M. and Platt, M.L. (2017)
Social Decision-Making and the Brain: A Comparative Perspective. Trends Cogn. Sci. 21, 265276.

12) Rushworth, M.F., Mars, R.B. and Sallet, J. (2013) Are there specialized circuits for social cognition and are they unique to humans? Curr. Opin. Neurobiol. 23, 436-442.

13) Sallet, J., Mars, R.B., Noonan, M.P., Neubert, F.X., Jbabdi, S., O'Reilly, J.X. et al. (2013) The organization of dorsal frontal cortex in humans and macaques. J. Neurosci. 33, 12255-12274.

14) Sallet, J., Mars, R.B., Noonan, M.P., Andersson, J.L., O'Reilly, J.X., Jbabdi, S. et al. (2011) Social network size affects neural circuits in macaques. Science 334, 697-700.

15) Bickart, K.C., Wright, C.I., Dautoff, R.J., Dickerson, B.C. and Barrett, L.F. (2011) Amygdala volume and social network size in humans. Nat. Neurosci. 14, 163-164.

16) Lewis, P.A., Rezaie, R., Brown, R., Roberts, N. and Dunbar, R.I. (2011) Ventromedial prefrontal volume predicts understanding of others and social network size. Neuroimage 57, 1624-1629.

17) Kanai, R., Bahrami, B., Roylance, R. and Rees, G. (2012) Online social network size is reflected in human brain structure. Proc. Biol. Sci. 279, $1327-1334$.

18) Deaner, R.O., Khera, A.V. and Platt, M.L. (2005) Monkeys pay per view: adaptive valuation of social images by rhesus macaques. Curr. Biol. 15, 543-548.

19) Rudebeck, P.H., Buckley, M.J., Walton, M.E. and Rushworth, M.F. (2006) A role for the macaque anterior cingulate gyrus in social valuation. Science 313, 1310-1312.

20) Watson, K.K. and Platt, M.L. (2012) Social signals in primate orbitofrontal cortex. Curr. Biol. 22, 2268-2273.

21) Noonan, M.P., Sallet, J., Rudebeck, P.H., Buckley, M.J. and Rushworth, M.F. (2010) Does the medial orbitofrontal cortex have a role in social valuation? Eur. J. Neurosci. 31, 2341-2351.

22) Klein, J.T., Deaner, R.O. and Platt, M.L. (2008) Neural correlates of social target value in macaque parietal cortex. Curr. Biol. 18, 419-424.

23) Matsumoto, M. and Hikosaka, O. (2009) Two types of dopamine neuron distinctly convey positive and negative motivational signals. Nature 459, 837-841.

24) Logothetis, N.K., Guggenberger, H., Peled, S. and Pauls, J. (1999) Functional imaging of the monkey brain. Nat. Neurosci. 2, 555-562.

25) Tsao, D.Y., Freiwald, W.A., Knutsen, T.A., Mandeville, J.B. and Tootell, R.B. (2003) Faces and objects in macaque cerebral cortex. Nat. Neurosci. 6, 989-995.

26) Pinsk, M.A., DeSimone, K., Moore, T., Gross, C.G. and Kastner, S. (2005) Representations of faces and body parts in macaque temporal cortex: a functional MRI study. Proc. Natl. Acad. Sci. U.S.A. 102, 6996-7001.

27) Perrett, D.I., Rolls, E.T. and Caan, W. (1982) 
Visual neurones responsive to faces in the monkey temporal cortex. Exp. Brain Res. 47, 329-342.

28) Desimone, R., Albright, T.D., Gross, C.G. and Bruce, C. (1984) Stimulus-selective properties of inferior temporal neurons in the macaque. J. Neurosci. 4, 2051-2062.

29) Baylis, G.C., Rolls, E.T. and Leonard, C.M. (1987) Functional subdivisions of the temporal lobe neocortex. J. Neurosci. 7, 330-342.

30) Tsao, D.Y., Freiwald, W.A., Tootell, R.B. and Livingstone, M.S. (2006) A cortical region consisting entirely of face-selective cells. Science $\mathbf{3 1 1}$, 670-674.

31) Moeller, S., Freiwald, W.A. and Tsao, D.Y. (2008) Patches with links: a unified system for processing faces in the macaque temporal lobe. Science $\mathbf{3 2 0}$, $1355-1359$.

32) Polosecki, P., Moeller, S., Schweers, N., Romanski, L.M., Tsao, D.Y. and Freiwald, W.A. (2013) Faces in motion: selectivity of macaque and human face processing areas for dynamic stimuli. J. Neurosci. 33, 11768-11773.

33) Tanaka, K. (1996) Inferotemporal cortex and object vision. Annu. Rev. Neurosci. 19, 109-139.

34) Wang, G., Tanaka, K. and Tanifuji, M. (1996) Optical imaging of functional organization in the monkey inferotemporal cortex. Science 272, $1665-1668$.

35) Harries, M.H. and Perrett, D.I. (1991) Visual processing of faces in temporal cortex: physiological evidence for a modular organization and possible anatomical correlates. J. Cogn. Neurosci. 3, 9-24.

36) Freiwald, W.A. and Tsao, D.Y. (2010) Functional compartmentalization and viewpoint generalization within the macaque face-processing system. Science 330, 845-851.

37) Kanwisher, N., McDermott, J. and Chun, M.M. (1997) The fusiform face area: a module in human extrastriate cortex specialized for face perception. J. Neurosci. 17, 4302-4311.

38) Minxha, J., Mosher, C., Morrow, J.K., Mamelak, A.N., Adolphs, R., Gothard, K.M. et al. (2017) Fixations Gate Species-Specific Responses to Free Viewing of Faces in the Human and Macaque Amygdala. Cell Reports 18, 878-891.

39) Mosher, C.P., Zimmerman, P.E. and Gothard, K.M. (2014) Neurons in the monkey amygdala detect eye contact during naturalistic social interactions. Curr. Biol. 24, 2459-2464.

40) Scalaidhe, S.P., Wilson, F.A. and Goldman-Rakic, P.S. (1999) Face-selective neurons during passive viewing and working memory performance of rhesus monkeys: evidence for intrinsic specialization of neuronal coding. Cereb. Cortex 9, 459475.

41) Rolls, E.T., Critchley, H.D., Browning, A.S. and Inoue, K. (2006) Face-selective and auditory neurons in the primate orbitofrontal cortex. Exp. Brain Res. 170, 74-87.

42) Tsao, D.Y., Moeller, S. and Freiwald, W.A. (2008) Comparing face patch systems in macaques and humans. Proc. Natl. Acad. Sci. U.S.A. 105, 19514-19519.

43) Vermeire, B.A., Hamilton, C.R. and Erdmann, A.L. (1998) Right-hemispheric superiority in splitbrain monkeys for learning and remembering facial discriminations. Behav. Neurosci. 112, 1048-1061.

44) Ifune, C.K., Vermeire, B.A. and Hamilton, C.R. (1984) Hemispheric differences in split-brain monkeys viewing and responding to videotape recordings. Behav. Neural Biol. 41, 231-235.

45) Hauser, M.D. (1993) Right hemisphere dominance for the production of facial expression in monkeys. Science 261, 475-477.

46) McCarthy, G., Puce, A., Gore, J.C. and Allison, T. (1997) Face-specific processing in the human fusiform gyrus. J. Cogn. Neurosci. 9, 605-610.

47) Puce, A., Allison, T., Asgari, M., Gore, J.C. and McCarthy, G. (1996) Differential sensitivity of human visual cortex to faces, letterstrings, and textures: a functional magnetic resonance imaging study. J. Neurosci. 16, 5205-5215.

48) De Renzi, E., Perani, D., Carlesimo, G.A., Silveri, M.C. and Fazio, F. (1994) Prosopagnosia can be associated with damage confined to the right hemisphere - an MRI and PET study and a review of the literature. Neuropsychologia 32, 893-902.

49) Hilliard, R.D. (1973) Hemispheric laterality effects on a facial recognition task in normal subjects. Cortex 9, 246-258.

50) Baron-Cohen, S. (1994) How to build a baby that reads minds: Cognitive mechanisms in mindreading. Curr. Psychol. Cogn. 13, 513-552.

51) Emery, N.J. (2000) The eyes have it: the neuroethology, function and evolution of social gaze. Neurosci. Biobehav. Rev. 24, 581-604.

52) Sato, N. and Nakamura, K. (2001) Detection of directed gaze in rhesus monkeys (Macaca mulatta). J. Comp. Psychol. 115, 115-121.

53) Perrett, D.I., Smith, P.A., Potter, D.D., Mistlin, A.J., Head, A.S., Milner, A.D. et al. (1985) Visual cells in the temporal cortex sensitive to face view and gaze direction. Proc. R. Soc. Lond. B Biol. Sci. 223, 293-317.

54) Jellema, T., Baker, C.I., Wicker, B. and Perrett, D.I. (2000) Neural representation for the perception of the intentionality of actions. Brain Cogn. 44, 280-302.

55) Campbell, R., Heywood, C.A., Cowey, A., Regard, M. and Landis, T. (1990) Sensitivity to eye gaze in prosopagnosic patients and monkeys with superior temporal sulcus ablation. Neuropsychologia 28, $1123-1142$.

56) Perrett, D.I., Hietanen, J.K., Oram, M.W. and Benson, P.J. (1992) Organization and functions of cells responsive to faces in the temporal cortex. Philos. Trans. R. Soc. Lond., B, Biol. Sci. 335, 23-30.

57) De Souza, W.C., Eifuku, S., Tamura, R., Nishijo, H. and Ono, T. (2005) Differential characteristics of face neuron responses within the anterior superior 
temporal sulcus of macaques. J. Neurophysiol. 94, $1252-1266$.

58) Tazumi, T., Hori, E., Maior, R.S., Ono, T. and Nishijo, H. (2010) Neural correlates to seen gazedirection and head orientation in the macaque monkey amygdala. Neuroscience 169, 287-301.

59) Aggleton, J.P., Burton, M.J. and Passingham, R.E. (1980) Cortical and subcortical afferents to the amygdala of the rhesus monkey (Macaca mulatta). Brain Res. 190, 347-368.

60) Shepherd, S.V. (2010) Following gaze: gaze-following behavior as a window into social cognition. Front. Integr. Neurosci. 4, 5.

61) Penn, D.C. and Povinelli, D.J. (2007) On the lack of evidence that non-human animals possess anything remotely resembling a 'theory of mind'. Philos. Trans. R. Soc. Lond., B, Biol. Sci. 362, 731-744.

62) Emery, N.J., Lorincz, E.N., Perrett, D.I., Oram, M.W. and Baker, C.I. (1997) Gaze following and joint attention in rhesus monkeys (Macaca mulatta). J. Comp. Psychol. 111, 286-293.

63) Shepherd, S.V., Deaner, R.O. and Platt, M.L. (2006) Social status gates social attention in monkeys. Curr. Biol. 16, R119-R120.

64) Deaner, R.O. and Platt, M.L. (2003) Reflexive social attention in monkeys and humans. Curr. Biol. 13, $1609-1613$.

65) Kumashiro, M., Ishibashi, H., Uchiyama, Y., Itakura, S., Murata, A. and Iriki, A. (2003) Natural imitation induced by joint attention in Japanese monkeys. Int. J. Psychophysiol. 50, 8199.

66) Rosati, A.G., Arre, A.M., Platt, M.L. and Santos, L.R. (2016) Rhesus monkeys show human-like changes in gaze following across the lifespan. Proc. R. Soc. Lond., B, Biol. Sci. 283, 20160376.

67) Putnam, P.T., Roman, J.M., Zimmerman, P.E. and Gothard, K.M. (2016) Oxytocin enhances gazefollowing responses to videos of natural social behavior in adult male rhesus monkeys. Psychoneuroendocrinology 72, 47-53.

68) Kamphuis, S., Dicke, P.W. and Thier, P. (2009) Neuronal substrates of gaze following in monkeys. Eur. J. Neurosci. 29, 1732-1738.

69) Roy, A., Shepherd, S.V. and Platt, M.L. (2014) Reversible inactivation of pSTS suppresses social gaze following in the macaque (Macaca mulatta). Soc. Cogn. Affect. Neurosci. 9, 209-217.

70) Seltzer, B. and Pandya, D.N. (1991) Post-rolandic cortical projections of the superior temporal sulcus in the rhesus monkey. J. Comp. Neurol. 312, 625640.

71) Goldberg, M.E., Bisley, J.W., Powell, K.D. and Gottlieb, J. (2006) Saccades, salience and attention: the role of the lateral intraparietal area in visual behavior. Prog. Brain Res. 155, 157-175.

72) Shepherd, S.V., Klein, J.T., Deaner, R.O. and Platt, M.L. (2009) Mirroring of attention by neurons in macaque parietal cortex. Proc. Natl. Acad. Sci. U.S.A. 106, 9489-9494.

73) Blatt, G.J., Andersen, R.A. and Stoner, G.R. (1990)
Visual receptive field organization and corticocortical connections of the lateral intraparietal area (area LIP) in the macaque. J. Comp. Neurol. 299, 421-445.

74) Boussaoud, D., Ungerleider, L.G. and Desimone, R. (1990) Pathways for motion analysis: cortical connections of the medial superior temporal and fundus of the superior temporal visual areas in the macaque. J. Comp. Neurol. 296, 462-495.

75) Ungerleider, L.G., Galkin, T.W., Desimone, R. and Gattass, R. (2008) Cortical connections of area V4 in the macaque. Cereb. Cortex 18, 477-499.

76) Moran, J. and Desimone, R. (1985) Selective attention gates visual processing in the extrastriate cortex. Science 229, 782-784.

77) Treue, S. and Maunsell, J.H. (1996) Attentional modulation of visual motion processing in cortical areas MT and MST. Nature 382, 539-541.

78) Chadwick-Jones, J. (1998) Developing a Social Psychology of Monkeys and Apes. Psychology Press, Hove, UK.

79) Fujii, N., Hihara, S., Nagasaka, Y. and Iriki, A. (2009) Social state representation in prefrontal cortex. Soc. Neurosci. 4, 73-84.

80) Fujii, N., Hihara, S. and Iriki, A. (2007) Dynamic social adaptation of motion-related neurons in primate parietal cortex. PLoS One 2, e397.

81) Santos, G.S., Nagasaka, Y., Fujii, N. and Nakahara, H. (2012) Encoding of social state information by neuronal activities in the macaque caudate nucleus. Soc. Neurosci. 7, 42-58.

82) Oosugi, N., Yanagawa, T., Nagasaka, Y. and Fujii, N. (2016) Social Suppressive Behavior Is Organized by the Spatiotemporal Integration of Multiple Cortical Regions in the Japanese Macaque. PLoS One 11, e0150934.

83) Noonan, M.P., Sallet, J., Mars, R.B., Neubert, F.X., O'Reilly, J.X., Andersson, J.L. et al. (2014) A neural circuit covarying with social hierarchy in macaques. PLoS Biol. 12, e1001940.

84) Bandura, A. and McDonald, F.J. (1963) Influence of Social Reinforcement and the Behavior of Models in Shaping Children's Moral Judgments. J. Abnorm. Psychol. 67, 274-281.

85) Mobbs, D., Yu, R., Meyer, M., Passamonti, L., Seymour, B., Calder, A.J. et al. (2009) A key role for similarity in vicarious reward. Science 324, 900.

86) Ballesta, S. and Duhamel, J.R. (2015) Rudimentary empathy in macaques' social decision-making. Proc. Natl. Acad. Sci. U.S.A. 112, 15516-15521.

87) Subiaul, F., Cantlon, J.F., Holloway, R.L. and Terrace, H.S. (2004) Cognitive imitation in rhesus macaques. Science 305, 407-410.

88) Falcone, R., Brunamonti, E. and Genovesio, A. (2012) Vicarious learning from human models in monkeys. PLoS One 7, e40283.

89) Falcone, R., Brunamonti, E., Ferraina, S. and Genovesio, A. (2012) Monkeys monitor human goals in a nonmatch-to-goal interactive task. PLoS One 7, e32209.

90) Gariepy, J.F., Watson, K.K., Du, E., Xie, D.L., Erb, 
J., Amasino, D. et al. (2014) Social learning in humans and other animals. Front. Neurosci. 8, 58.

91) Chang, S.W., Winecoff, A.A. and Platt, M.L. (2011) Vicarious reinforcement in rhesus macaques (macaca mulatta). Front. Neurosci. 5, 27.

92) Chang, S.W., Barter, J.W., Ebitz, R.B., Watson, K.K. and Platt, M.L. (2012) Inhaled oxytocin amplifies both vicarious reinforcement and self reinforcement in rhesus macaques (Macaca mulatta). Proc. Natl. Acad. Sci. U.S.A. 109, 959-964.

93) Chang, S.W., Gariepy, J.F. and Platt, M.L. (2013) Neuronal reference frames for social decisions in primate frontal cortex. Nat. Neurosci. 16, 243250.

94) Chang, S.W., Fagan, N.A., Toda, K., Utevsky, A.V., Pearson, J.M. and Platt, M.L. (2015) Neural mechanisms of social decision-making in the primate amygdala. Proc. Natl. Acad. Sci. U.S.A. 112, 16012-16017.

95) Adolphs, R. (2010) What does the amygdala contribute to social cognition? Ann. N. Y. Acad. Sci. 1191, 42-61.

96) Gothard, K.M., Battaglia, F.P., Erickson, C.A., Spitler, K.M. and Amaral, D.G. (2007) Neural responses to facial expression and face identity in the monkey amygdala. J. Neurophysiol. 97, 16711683.

97) Hoffman, K.L., Gothard, K.M., Schmid, M.C. and Logothetis, N.K. (2007) Facial-expression and gaze-selective responses in the monkey amygdala. Curr. Biol. 17, 766-772.

98) Baez-Mendoza, R., Harris, C.J. and Schultz, W. (2013) Activity of striatal neurons reflects social action and own reward. Proc. Natl. Acad. Sci. U.S.A. 110, 16634-16639

99) Hosokawa, T. and Watanabe, M. (2012) Prefrontal neurons represent winning and losing during competitive video shooting games between monkeys. J. Neurosci. 32, 7662-7671.

100) Hosokawa, T. and Watanabe, M. (2015) Egalitarian reward contingency in competitive games and primate prefrontal neuronal activity. Front. Neurosci. 9, 165

101) Azzi, J.C., Sirigu, A. and Duhamel, J.R. (2012) Modulation of value representation by social context in the primate orbitofrontal cortex. Proc. Natl. Acad. Sci. U.S.A. 109, 2126-2131.

102) Meunier, M., Monfardini, E. and Boussaoud, D. (2007) Learning by observation in rhesus monkeys. Neurobiol. Learn. Mem. 88, 243-248.

103) Monfardini, E., Gaveau, V., Boussaoud, D., HadjBouziane, F. and Meunier, M. (2012) Social learning as a way to overcome choice-induced preferences? Insights from humans and rhesus macaques. Front. Neurosci. 6, 127.

104) Van Overwalle, F. and Baetens, K. (2009) Understanding others' actions and goals by mirror and mentalizing systems: a meta-analysis. Neuroimage 48, 564-584.

105) di Pellegrino, G., Fadiga, L., Fogassi, L., Gallese, V. and Rizzolatti, G. (1992) Understanding motor events: a neurophysiological study. Exp. Brain Res. 91, 176-180.

106) Rizzolatti, G. and Sinigaglia, C. (2010) The functional role of the parieto-frontal mirror circuit: interpretations and misinterpretations. Nat. Rev. Neurosci. 11, 264-274.

107) Kraskov, A., Dancause, N., Quallo, M.M., Shepherd, S. and Lemon, R.N. (2009) Corticospinal neurons in macaque ventral premotor cortex with mirror properties: a potential mechanism for action suppression? Neuron 64, 922-930.

108) Hickok, G. (2009) Eight problems for the mirror neuron theory of action understanding in monkeys and humans. J. Cogn. Neurosci. 21, 1229-1243.

109) Gallese, V. and Goldman, A. (1998) Mirror neurons and the simulation theory of mind-reading. Trends Cogn. Sci. 2, 493-501.

110) Rizzolatti, G. and Fabbri-Destro, M. (2010) Mirror neurons: from discovery to autism. Exp. Brain Res. 200, 223-237.

111) Iacoboni, M. (2009) Imitation, empathy, and mirror neurons. Annu. Rev. Psychol. 60, 653-670.

112) Ramachandran, V.S. and Oberman, L.M. (2006) Broken mirrors: a theory of autism. Sci. Am. 295, 62-69.

113) Williams, J.H., Whiten, A., Suddendorf, T. and Perrett, D.I. (2001) Imitation, mirror neurons and autism. Neurosci. Biobehav. Rev. 25, 287-295.

114) Maranesi, M., Livi, A., Fogassi, L., Rizzolatti, G. and Bonini, L. (2014) Mirror neuron activation prior to action observation in a predictable context. J. Neurosci. 34, 14827-14832.

115) Vigneswaran, G., Philipp, R., Lemon, R.N. and Kraskov, A. (2013) M1 corticospinal mirror neurons and their role in movement suppression during action observation. Curr. Biol. 23, 236243.

116) Bonini, L., Maranesi, M., Livi, A., Fogassi, L. and Rizzolatti, G. (2014) Ventral premotor neurons encoding representations of action during self and others' inaction. Curr. Biol. 24, 1611-1614.

117) Caggiano, V., Fogassi, L., Rizzolatti, G., Casile, A., Giese, M.A. and Thier, P. (2012) Mirror neurons encode the subjective value of an observed action. Proc. Natl. Acad. Sci. U.S.A. 109, 11848-11853.

118) Caggiano, V., Fogassi, L., Rizzolatti, G., Thier, P. and Casile, A. (2009) Mirror neurons differentially encode the peripersonal and extrapersonal space of monkeys. Science 324, 403-406.

119) Caggiano, V., Giese, M., Thier, P. and Casile, A. (2015) Encoding of point of view during action observation in the local field potentials of macaque area F5. Eur. J. Neurosci. 41, 466-476.

120) Caggiano, V., Fleischer, F., Pomper, J.K., Giese, M.A. and Thier, P. (2016) Mirror Neurons in Monkey Premotor Area F5 Show Tuning for Critical Features of Visual Causality Perception. Curr. Biol. 26, 3077-3082.

121) Isoda, M. (2016) Understanding intentional actions from observers' viewpoints: A social neuroscience perspective. Neurosci. Res. 112, 1-9.

122) Isoda, M. and Noritake, A. (2013) What makes the 
dorsomedial frontal cortex active during reading the mental states of others? Front. Neurosci. 7, 232.

123) Denny, B.T., Kober, H., Wager, T.D. and Ochsner, K.N. (2012) A meta-analysis of functional neuroimaging studies of self- and other judgments reveals a spatial gradient for mentalizing in medial prefrontal cortex. J. Cogn. Neurosci. 24, 17421752.

124) Yoshida, K., Saito, N., Iriki, A. and Isoda, M. (2011) Representation of others' action by neurons in monkey medial frontal cortex. Curr. Biol. 21, 249-253.

125) Falcone, R., Cirillo, R., Ferraina, S. and Genovesio, A. (2017) Neural activity in macaque medial frontal cortex represents others' choices. Sci. Rep. 7, 12663 .

126) Haroush, K. and Williams, Z.M. (2015) Neuronal prediction of opponent's behavior during cooperative social interchange in primates. Cell 160, $1233-1245$.

127) Yoshida, K., Go, Y., Kushima, I., Toyoda, A., Fujiyama, A., Imai, H. et al. (2016) Single-neuron and genetic correlates of autistic behavior in macaque. Sci. Adv. 2, e1600558.

128) Oberman, L.M., Hubbard, E.M., McCleery, J.P., Altschuler, E.L., Ramachandran, V.S. and Pineda, J.A. (2005) EEG evidence for mirror neuron dysfunction in autism spectrum disorders. Brain Res. Cogn. Brain Res. 24, 190-198.

129) Martineau, J., Cochin, S., Magne, R. and Barthelemy, C. (2008) Impaired cortical activation in autistic children: is the mirror neuron system involved? Int. J. Psychophysiol. 68, 3540.

130) Muthukumaraswamy, S.D., Johnson, B.W. and McNair, N.A. (2004) Mu rhythm modulation during observation of an object-directed grasp. Brain Res. Cogn. Brain Res. 19, 195-201.

131) Konopka, G. (2017) Cognitive genomics: linking genes to behavior in the human brain. Netw. Neurosci. 1, 3-13.

132) Izquierdo, A., Newman, T.K., Higley, J.D. and Murray, E.A. (2007) Genetic modulation of cognitive flexibility and socioemotional behavior in rhesus monkeys. Proc. Natl. Acad. Sci. U.S.A. 104, 14128-14133.

133) Watson, K.K., Ghodasra, J.H. and Platt, M.L. (2009) Serotonin transporter genotype modulates social reward and punishment in rhesus macaques. PLoS One 4, e4156.

134) Chen, G.L., Novak, M.A., Meyer, J.S., Kelly, B.J., Vallender, E.J. and Miller, G.M. (2010) The effect of rearing experience and TPH2 genotype on HPA axis function and aggression in rhesus monkeys: a retrospective analysis. Horm. Behav. 57, 184-191.

135) Brent, L.J., Heilbronner, S.R., Horvath, J.E., Gonzalez-Martinez, J., Ruiz-Lambides, A., Robinson, A.G. et al. (2013) Genetic origins of social networks in rhesus macaques. Sci. Rep. 3, 1042.

136) Sanchez-Danes, A., Richaud-Patin, Y., Carballo-
Carbajal, I., Jimenez-Delgado, S., Caig, C., Mora, S. et al. (2012) Disease-specific phenotypes in dopamine neurons from human iPS-based models of genetic and sporadic Parkinson's disease. EMBO Mol. Med. 4, 380-395.

137) Shiba, Y., Gomibuchi, T., Seto, T., Wada, Y., Ichimura, H., Tanaka, Y. et al. (2016) Allogeneic transplantation of iPS cell-derived cardiomyocytes regenerates primate hearts. Nature 538, 388-391.

138) Foust, K.D., Wang, X., McGovern, V.L., Braun, L., Bevan, A.K., Haidet, A.M. et al. (2010) Rescue of the spinal muscular atrophy phenotype in a mouse model by early postnatal delivery of SMN. Nat. Biotechnol. 28, 271-274.

139) Meyer, K., Ferraiuolo, L., Schmelzer, L., Braun, L., McGovern, V., Likhite, S. et al. (2015) Improving single injection CSF delivery of AAV9-mediated gene therapy for SMA: a dose-response study in mice and nonhuman primates. Mol. Ther. 23, 477-487.

140) Kinoshita, M., Matsui, R., Kato, S., Hasegawa, T., Kasahara, H., Isa, K. et al. (2012) Genetic dissection of the circuit for hand dexterity in primates. Nature 487, 235-238.

141) Yoshida, K., Saito, N., Iriki, A. and Isoda, M. (2012) Social error monitoring in macaque frontal cortex. Nat. Neurosci. 15, 1307-1312.

142) Baez-Mendoza, R. and Schultz, W. (2016) Performance error-related activity in monkey striatum during social interactions. Sci. Rep. 6, 37199.

143) Inase, M., Tokuno, H., Nambu, A., Akazawa, T. and Takada, M. (1999) Corticostriatal and corticosubthalamic input zones from the presupplementary motor area in the macaque monkey: comparison with the input zones from the supplementary motor area. Brain Res. 833, 191-201.

144) Hietanen, J.K. and Perrett, D.I. (1993) Motion sensitive cells in the macaque superior temporal polysensory area. I. Lack of response to the sight of the animal's own limb movement. Exp. Brain Res. 93, 117-128.

145) Barbas, H., Ghashghaei, H., Dombrowski, S.M. and Rempel-Clower, N.L. (1999) Medial prefrontal cortices are unified by common connections with superior temporal cortices and distinguished by input from memory-related areas in the rhesus monkey. J. Comp. Neurol. 410, 343-367.

146) Seltzer, B. and Pandya, D.N. (1989) Frontal lobe connections of the superior temporal sulcus in the rhesus monkey. J. Comp. Neurol. 281, 97-113.

147) Luppino, G., Calzavara, R., Rozzi, S. and Matelli, M. (2001) Projections from the superior temporal sulcus to the agranular frontal cortex in the macaque. Eur. J. Neurosci. 14, 1035-1040.

148) Brothers, L. (1990) The social brain: A project for integrating primate behavior and neurophysiolgy in a new domain. Concepts Neurosci. 1, 27-51.

149) Decety, J. and Sommerville, J.A. (2003) Shared representations between self and other: a social cognitive neuroscience view. Trends Cogn. Sci. 7, $527-533$. 
150) Hecht, D. (2014) Cerebral lateralization of pro- and anti-social tendencies. Exp. Neurobiol. 23, 1-27.

151) Luppino, G., Matelli, M., Camarda, R. and Rizzolatti, G. (1993) Corticocortical connections of area F3 (SMA-proper) and area F6 (pre-SMA) in the macaque monkey. J. Comp. Neurol. 338, $114-140$.

152) Rizzolatti, G. and Luppino, G. (2001) The cortical motor system. Neuron 31, 889-901.

153) Rozzi, S., Calzavara, R., Belmalih, A., Borra, E., Gregoriou, G.G., Matelli, M. et al. (2006) Cortical connections of the inferior parietal cortical convexity of the macaque monkey. Cereb. Cortex $\mathbf{1 6}$, 1389-1417.

154) Becchio, C., Cavallo, A., Begliomini, C., Sartori, L., Feltrin, G. and Castiello, U. (2012) Social grasping: from mirroring to mentalizing. Neuroimage 61, 240-248.

155) Cavallo, A., Lungu, O., Becchio, C., Ansuini, C., Rustichini, A. and Fadiga, L. (2015) When gaze opens the channel for communication: Integrative role of IFG and MPFC. Neuroimage 119, 63-69.

156) Sperduti, M., Guionnet, S., Fossati, P. and Nadel, J. (2014) Mirror Neuron System and Mentalizing System connect during online social interaction. Cogn. Process. 15, 307-316.

157) Klein, J.T., Shepherd, S.V. and Platt, M.L. (2009) Social attention and the brain. Curr. Biol. 19 R958-R962.

158) Di Paolo, E. and De Jaegher, H. (2012) The interactive brain hypothesis. Front. Hum. Neurosci. 6, 163

159) De Jaegher, H., Di Paolo, E. and Adolphs, R. (2016) What does the interactive brain hypothesis mean for social neuroscience? A dialogue. Philos. Trans. R. Soc. Lond., B, Biol. Sci. 371, 20150379.

160) De Jaegher, H., Di Paolo, E. and Gallagher, S. (2010) Can social interaction constitute social cognition? Trends Cogn. Sci. 14, 441-447.

161) Saito, D.N., Tanabe, H.C., Izuma, K., Hayashi, M.J., Morito, Y., Komeda, H. et al. (2010) "Stay tuned": inter-individual neural synchronization during mutual gaze and joint attention. Front. Integr. Neurosci. 4, 127.

162) Koike, T., Tanabe, H.C., Okazaki, S., Nakagawa, E., Sasaki, A.T., Shimada, K. et al. (2016) Neural substrates of shared attention as social memory: A hyperscanning functional magnetic resonance imaging study. Neuroimage 125, 401-412.

163) Funane, T., Kiguchi, M., Atsumori, H., Sato, H., Kubota, K. and Koizumi, H. (2011) Synchronous activity of two people's prefrontal cortices during a cooperative task measured by simultaneous near-infrared spectroscopy. J. Biomed. Opt. 16.
077011.

164) Balconi, M. and Vanutelli, M.E. (2017) Interbrains cooperation: Hyperscanning and self-perception in joint actions. J. Clin. Exp. Neuropsychol. 39, $607-620$.

165) Hirsch, J., Zhang, X., Noah, J.A. and Ono, Y. (2017) Frontal temporal and parietal systems synchronize within and across brains during live eye-to-eye contact. Neuroimage 157, 314-330.

166) Scholkmann, F., Holper, L., Wolf, U. and Wolf, M. (2013) A new methodical approach in neuroscience: assessing inter-personal brain coupling using functional near-infrared imaging (fNIRI) hyperscanning. Front. Hum. Neurosci. 7, 813.

167) Cheng, X., Li, X. and Hu, Y. (2015) Synchronous brain activity during cooperative exchange depends on gender of partner: A fNIRS-based hyperscanning study. Hum. Brain Mapp. 36, 2039-2048.

168) Dumas, G., Nadel, J., Soussignan, R., Martinerie, J. and Garnero, L. (2010) Inter-brain synchronization during social interaction. PLoS One 5, e12166.

169) Gallotti, M. and Frith, C.D. (2013) Social cognition in the we-mode. Trends Cogn. Sci. 17, 160-165.

170) Nagasaka, Y., Chao, Z.C., Hasegawa, N., Notoya, T. and Fujii, N. (2013) Spontaneous synchronization of arm motion between Japanese macaques. Sci. Rep. 3, 1151.

171) Ballesta, S., Mosher, C.P., Szep, J., Fischl, K.D. and Gothard, K.M. (2016) Social determinants of eyeblinks in adult male macaques. Sci. Rep. 6, 38686 .

172) Machiyama, Y., Utena, H. and Kikuchi, M. (1970) Behavioral disorders in Japanese monkeys produced by the long-term administration of methamphetamine. Proc. Jpn. Acad. 46, 738-743.

173) Ballesta, S., Reymond, G., Pozzobon, M. and Duhamel, J.R. (2014) A real-time 3D video tracking system for monitoring primate groups. J. Neurosci. Methods 234, 147-152.

174) Ballesta, S., Reymond, G., Pozzobon, M. and Duhamel, J.R. (2014) Compete to play: trade-off with social contact in long-tailed macaques (Macaca fascicularis). PLoS One 9, e115965.

175) Ballesta, S., Reymond, G., Pozzobon, M. and Duhamel, J.R. (2016) Effects of MDMA Injections on the Behavior of Socially-Housed Long-Tailed Macaques (Macaca fascicularis). PLoS One 11, $\mathrm{e} 0147136$.

(Received Mar. 29, 2018; accepted May 25, 2018) 


\section{Profile}

Masaki Isoda was born in Niigata Prefecture in 1969. He graduated from Niigata University School of Medicine in 1994. After five years of clinical training as a neurologist at the Brain Research Institute of Niigata University, he turned his career to basic research work in the field of neuroscience. Since then, he has been working as a systems neurophysiologist on clarifying neuronal mechanisms underlying cognitive control of behavior using macaque monkeys. He received a Ph.D. degree in 2003 from Tohoku University and then worked as a postdoctoral research fellow at the National Institutes of Health in the United States. He then became a Research Scientist at the RIKEN Brain Science Institute (2007-2010), a Principal Investigator at the Okinawa Institute of Science and Technology (2010-2012), an Associate Professor at the Kansai Medical

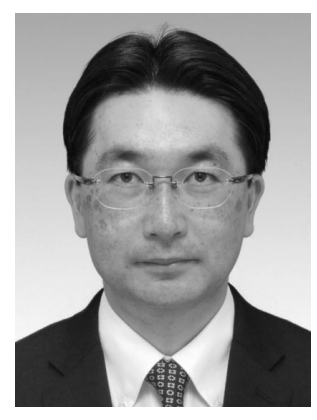
University School of Medicine (2012-2016), and a Professor at the National Institute for Physiological Sciences (2016-present). Currently, his primary research interest is in a systems-level understanding of social cognitive functions in physiology and disease. For his achievement, he received a Young Investigator Award from the Japan Neuroscience Society in 2009 and a Tsukahara Nakaakira Memorial Award from the Brain Science Foundation in 2017. 